PROCEEDINGS OF THE WORLD CONFERENCE ON OZONE THERAPY IN MEDICINE, DENTISTRY AND VETERINARY. ANCONA (ITALY). SEPTEMBER 22nd - 23rd - 24th, 2017

\title{
Ozone Therapy in Dentistry: Recognition from Brazilian Authorities [abstract]
}

\author{
Maria Emilia Gadelha-Serra \\ Brazilian Association of Ozonetherapy, Sao Paulo, Brazil.
}

\section{ABSTRACT}

\section{ठิ OPEN ACCESS}

\section{Citation}

Gadelha-Serra ME. Ozone Therapy in Dentistry: Recognition from Brazilian Authorities [abstract]. Proceedings of The World Conference on Ozone Therapy in Medicine, Dentistry and Veterinary. Ancona (Italy). September 22nd - 23rd - 24th , 2017. J Ozone Ther. 2019;3(4):41-42. doi: 10.7203/ jo3t.3.4.2019.15524

\section{Academic Editor \\ Jose Baeza-Noci, \\ School of Medicine, Valencia \\ University, SPAIN}

\section{Editor}

World Federation of Ozone Therapy, Bolgna, ITALY

\section{Received}

June 17, 2019

\section{Accepted}

December 08, 2019

Published

December 30, 2019

\section{Intellectual Property}

Maria Emilia Gadelha-Serra.

This is an open access article distributed under the terms of the Creative Commons Attribution License (CC BY 4.0), which permits unrestricted use, distribution, and reproduction in any medium, provided the original author and source are credited.

\section{Author Information}

emilia.gadelha1@gmail.com
This document aims to record the recognition of Ozone Therapy in Brazilian Dentistry, since the founding of the Brazilian Association of Ozonetherapy (ABOZ) in 2006.

$\mathrm{ABOZ}$ is a multi-professional association that congregates medical doctors, dentists, veterinarian doctors, nurses and related nursing professions, biologists, biomedicals professionals, physiotherapists and pharmacists from various parts of Brazil.

ABOZ's Mission is "to stimulate the development and diffusion of Ozone Therapy in Brazil in a legal, safe, scientific and ethical way, providing information and training of excellence, to benefit human and animal health" and its Vision is "to be an organization of technical and scientific reference of Ozone Therapy in Brazil and in the world".

In order to accomplish its mission and vision, along with one of its most important goals ("to ensure respect for professional ethics and work for the defense, regulation and supervision of the exercise of Ozone Therapy in Brazil"), ABOZ has taken many actions to recognize Ozone Therapy as a tool to be used also by Brazilian dentists. Two members of ABOZ's Board of Directors, the dentists Carlos Nogales and Francisco de Campos, were designated to help thinking of a strategy to make them come true. In January 2014, during the 32nd International Congress of Dentistry of São Paulo (CIOSP), the largest dental congress in the country, ABOZ was represented in this great event by Dr. Nogales, at the stand of the Regional Council of Sectional Dentistry of São Paulo (Conselho Regional de Odontologia de São Paulo - CROSP), with the purpose of collecting signatures for legalizing Ozone Therapy as an official dental procedure in Brazil. More than 200 signatures were collected. After that, a technical report was prepared to be presented to the Federal Council of Dentistry (CFO - Conselho Federal de Odontologia). On the same year (October 2014), at the National Assembly of Dental Specialities (Assembléia Nacional de Especialidades - Odontológicas - ANEO), a discussion of topics of interest to the class and revision of the legislation was started. This accredited the Ozone Therapy to be presented to the General Assembly of the CFO. At that time, the team was composed by ABOZ's Dentistry members, recognized specialists in their fields. In September 2015, there was the meeting of the CROSP and the topic of Ozone Therapy was discussed and voted on the approval to whether or not proceed with the process. ABOZ obtained $76 \%$ favorable votes.

The CFO's Board of Advisors finally deliberated on the results of the previous meeting and in December 8th , 2015 the CFO Resolution 166/2015 and its annex, which recognizes Ozone Therapy as a dental procedure to be 
applied in Dentistry and allows the dentist to indicate and apply the therapy, through training and certification after a qualification course (32 hours minimum) issued by Institution of higher education", was published in the Official Gazette of the Union. Dentistry's areas are treatment of dental caries, Periodontics, Endodontics, Surgery, TMJ pain and dysfunction and in treatment of necrosis of the jaw. ABOZ's values (Ethics, Scientific Innovation, Systemic Vision of Health, Quality of Life) were fully achieved for the benefit of the Brazilian People and Dentists. 